\title{
Desenvolvimento de capacidades discursivas e cidadania no PIBID
}

Discursive capacities development and citizenship in PIBID

\author{
Ana Cecilia Teixeira Gonçalves* (iD \\ acgteixeira@uffs.edu.br \\ http://orcid.org/0000-0003-4262-4578
}

\author{
Jeize de Fátima Batista** (iD) \\ jeize.batista@uffs.edu.br \\ http://orcid.org/0000-0003-1301-050X
}

\author{
Demétrio Alves Paz ${ }^{* \star *}$ (D) \\ demetrio.paz@uffs.edu.br \\ http://orcid.org/0000-0002-5305-290X
}

\begin{abstract}
Resumo
Este artigo apresenta reflexões e dois relatos de práticas, oriundos do PIBID, relacionados ao uso de textos literários no ensino de Língua Portuguesa na escola de Educação Básica. Assim, a fundamentação teórica que embasa o trabalho voltase, primeiramente, para a formação de professores, tendo em vista a relação entre o PIBID e o fazer-se docente, assim como o ensino de leitura e de literatura na escola. Nas atividades, priorizou-se a utilização do texto literário como ponto de partida para se trabalharem capacidades discursivas: ler, interpretar, refletir, analisar e produzir textos. Os alunos leram o romance Dom Casmurro, de Machado de Assis, e o conto "As mãos dos pretos", de Luís Bernardo Honwana. Com a experiência, percebeu-se que é possível propor práticas de leitura de textos literários que favoreçam a produção de sentidos e contribuam para o processo de constituição e humanização dos alunos enquanto sujeitos.
\end{abstract}

Palavras-chave: Aula de Língua Portuguesa; Texto literário; Formação de leitores; Docentes em formação; Letramento.

\footnotetext{
* Universidade Federal da Fronteira Sul (UFFS), Cerro Largo, RS, Brasil.

** Universidade Federal da Fronteira Sul (UFFS), Cerro Largo, RS, Brasil.

*** Universidade Federal da Fronteira Sul (UFFS), Cerro Largo, RS, Brasil.
}

\section{LINHA DÁGUA}




\begin{abstract}
This paper presents reflections and two activities reports, carried out within PIBID, related to the use of literary texts in Portuguese Language teaching in primary School. Therefore, the theoretical basis used in this work turns primarily to teachers' training, bearing in mind the relation between PIBID and being a teacher, as well as reading and literature teaching in school. In the activities, priority was given to the use of literary texts as a starting point to deal with the following discursive capacities: reading, interpretation, reflection, analysis and writing. The students read the novel Dom Casmurro, by Machado de Assis, and the short story "As mãos dos pretos", by Luís Bernardo Honwana. From this experience, the paper concludes that it is possible to propose reading activities using literary texts that contribute to meaning production and promote the process of constitution and humanization of students as subjects.
\end{abstract}

Keywords: Portuguese Language class; Literary text; Readers' formation; Teaching formation; Literacy.

\title{
Introdução
}

O presente artigo tem por objetivo apresentar reflexões e dois relatos de práticas, oriundos do Programa Institucional de Bolsas de Iniciação à Docência (PIBID), relacionados ao uso de textos literários no ensino de Língua Portuguesa em escolas públicas de Educação Básica. As práticas relatadas ocorreram em duas escolas que possuem bolsistas do programa desde 2017. A primeira prática descrita ocorreu em 2019 e a segunda em 2017.

Nesse sentido, para dar conta do objetivo proposto, este trabalho divide-se em três partes: na primeira parte, observa-se a relação entre o PIBID e a prática docente; na segunda, retomam-se ideias de estudiosos da linguagem sobre leitura, produção textual, ensino de leitura e literatura na escola; na terceira, relatam-se as práticas e comentam-se os procedimentos didáticos envolvidos. Como aporte teórico, tomou-se por base as obras de Antunes (2003), Bakhtin (2006), Cosson (2011), Geraldi (2010), Kato (1999), Kleiman (2000), Leffa (1996), Orlandi (1996a, 1996b), Soares (2012) entre outros. Além do apoio teórico, é relevante destacar que a experiência dos professores do curso de Letras - autores deste artigo - foi fundamental. Assim, destacam-se as atividades desenvolvidas ou em andamento pelos coordenadores do PIBID, tais como: a coordenação de projetos de pesquisa e de extensão (estes voltados à formação continuada de professores), a experiência em sala de aula, tanto no Ensino Fundamental e Médio quanto no Ensino Superior, as quais contribuíram consideravelmente para o desenvolvimento deste trabalho.

\section{PIBID e a formação do professor de língua(gem)}

A formação de docentes, especificamente em licenciatura, consiste em uma construção permeada por diversas experiências, as quais permitem que o sujeito, na qualidade de professor

\section{LINHA DÁGUA}


em desenvolvimento, consiga adquirir diferentes perspectivas, concepções e aprendizagens por meio de práticas e de teorias aplicadas no âmbito da escola.

Nesse contexto, o PIBID representa uma oportunidade de inserir o professor, desde o início de seu percurso formativo, no contexto escolar, promovendo sua qualificação e o instituindo como profissional docente. Com isso, não só se potencializa a qualidade da formação inicial de professores nos cursos de licenciatura, mas também se abre possibilidade para que Educação Superior e Básica interajam, o que é de extrema relevância.

De acordo com Gehring e Castela (2016), muitos estudos da área da educação relatam que, para haver melhorias no processo de ensino e de aprendizagem, sobretudo na Educação Básica, é necessário que se intensifique a interação entre a escola e a universidade. Esse, inclusive, é um dos principais objetivos do PIBID, o qual busca potencializar a formação profissional de muitos professores. É por meio do PIBID que "o licenciando tem a oportunidade de elaborar sua profissionalidade docente, dialogando entre os conhecimentos acadêmicos e os conhecimentos experienciais, integrando a teoria à prática, o que é considerado fundamental para a formação de professores" (GEHRING; CASTELA, 2016, p. 110).

Essa experiência permite ao licenciando vivenciar a prática na sala de aula, construindo aprendizagens e contribuindo para formação da identidade profissional. Assim, ela é compreendida como campo de conhecimento e práxis, o que a define como uma experiência investigativa que envolve a elaboração, aplicação, reflexão e transformação do processo de ensinar. Dessa forma, o diálogo entre a teoria - apreendida nos encontros de formação do PIBID e no Curso de Letras - e a prática - vivenciada nas escolas-campo - contribuem como espaços de observações, análises e descobertas, sendo, nesse sentido, instrumentos indissociáveis no processo de formação docente.

Sob esse viés, para o desenvolvimento da atividade docente, em especial na área de Língua Portuguesa, acredita-se que é de suma importância levar para a sala de aula o recorte de contextos reais, por meio do debate de temáticas sociais que façam parte da vida do estudante, instigando-o a refletir e a se posicionar criticamente perante fatos observados. Ademais, devese trabalhar com contextos fictícios, a partir de textos literários, os quais permitam a leitura prazerosa, a fruição estética e o alargamento da visão de mundo do estudante. A aula de Língua Portuguesa, nessa perspectiva, pode ser considerada um acontecimento: "trata-se de pensar o ensino não como aprendizagem do conhecido, mas como produção de conhecimentos, que resultam, de modo geral, de novas articulações entre conhecimentos disponíveis" (GERALDI, 2010, pp. 97-98). Assim, o processo metodológico deve ser planejado e pensado tendo-se em vista o conhecimento que o estudante traz para a escola e o conhecimento que ele pode adquirir com a escola:

Os conhecimentos que [...] se recriam na escola ganham sentido quando são produtos de uma construção dinâmica que se opera na interação constante entre o saber escolar e os demais saberes, entre o que o aluno aprende na escola e o que ele traz para a escola, num processo contínuo e permanente de aquisição, no qual interferem fatores políticos, sociais, culturais e psicológicos (BRASIL, 1998, p. $34)$.

\section{LINHA DÁGUA}


As aulas de Língua Portuguesa são um espaço que tem como finalidade proporcionar aos sujeitos o desenvolvimento da capacidade de ler, de interagir, analisar, compreender, refletir e produzir novos textos a partir do uso da linguagem, tendo cada vez mais acesso às informações e construindo diversas visões sobre o mundo através de diferentes práticas sociodiscursivas. Nesse sentido, conforme Santos (1996, p. 25),

A finalidade maior no ensino de Português baseado na expressão livre do aluno não é somente favorecer-lhe o domínio do código linguístico, mas é também e principalmente por meio desse domínio criar condições favoráveis para que ele indivíduo e ser social co-detentor e co-construtor de uma cultura - possa tornar-se cada vez mais independente e capaz de enfrentar com o máximo de realização, o seu destino de homem e cidadão.

Sendo assim, de modo a possibilitar ao discente tornar-se um cidadão crítico e exercer seus deveres e direitos na sociedade, há algumas habilidades que devem ser desenvolvidas em Língua Portuguesa. De acordo com documentos oficiais que planificam o ensino dessa área, os alunos deverão ser capazes de se posicionarem, relacionando o que foi estudado com situações cotidianas, aplicando esses conhecimentos em contextos reais de uso. Para que isso ocorra, o objeto de estudo das aulas de Língua Portuguesa deve ser o texto: "são os textos que favorecem a reflexão crítica e imaginativa, o exercício de formas de pensamento mais elaboradas e abstratas, vitais para a plena participação numa sociedade letrada” (BRASIL, 1997, p.26).

Nesse mesmo sentido, em relação ao ensino de Língua Portuguesa na Educação Básica, Marcuschi (2001, p. 30) ressalta que:

É importante ter em mente que o ensino de língua na escola não visa a formar linguistas ou gramáticos e muito menos analistas da fala, analistas de texto ou conversação. Tudo se resume a este objetivo: ensinar os alunos a perceberem a riqueza que envolve o uso efetivo da língua como um patrimônio maior do qual não podemos abrir mão. Pois, se há um estudo que vale a pena no ensino básico, é o estudo da língua e suas possibilidades. A língua será a grande ferramenta diária da qual ninguém poderá abdicar durante toda sua vida, venha ela a fazer seja lá o que for.

Desse modo, um estudo da língua de forma contextualizada oportuniza reflexões, análises e comparações sobre as múltiplas possibilidades de uso da linguagem, bem como suas aplicações e variações. Cabe destacar, ainda, que, para atingir essas habilidades, o professor tem um papel fundamental: mediar o processo de aprendizagem dos alunos, a partir do desenvolvimento de suas aulas as quais devem articular práticas sociais e linguísticas. O texto passa, então, a ser colocado como princípio das aulas de Língua Portuguesa, rompendo a ideia de um ensino por meio de frases soltas: “o texto é único como enunciado, mas múltiplo enquanto possibilidade aberta de atribuição de significados, devendo, portanto, ser objeto também único de análise/síntese" (BRASIL, 2000, p. 18-19).

Sobre este ponto, Antunes (2007 p. 129) salienta que "a aprendizagem dos nomes e das classificações é apenas uma parte - talvez, a menos significativa, - do estudo das gramáticas”. O foco, portanto, deve estar no processo interativo de uso daquilo que se está aprendendo.

\section{LINHA D'́GUA}


Partindo disso, buscou-se desenvolver, junto aos alunos do PIBID, reflexões teóricopráticas a fim de compreender os processos de ensinar e de aprender a Língua Portuguesa, de modo que se trabalhou não só com a construção de conceitos de leitura de diferentes espécies de textos - inclusive o literário -, mas também com os de escrita, interpretação, compreensão, análise linguística e produção textual, tendo como objeto de ensino o texto, materialidade que representa a articulação entre práticas sociais e atividades de linguagem.

Isso posto, acredita-se que as questões metodológicas devem voltar-se para um ensino de qualidade, dinâmico, interativo, que busca formar cidadãos capazes de interferir criticamente na realidade para transformá-la, respeitando os conhecimentos que os alunos trazem consigo, permitindo reflexão e diálogo entre os diferentes saberes. Deve, também, privilegiar o aspecto artístico, apresentando a literatura e a singularidade de seus textos, e proporcionando a constituição de um leitor literário. Nesse sentido, o texto literário passa a ser um instrumento riquíssimo e uma fonte inesgotável de construção de saberes que envolvem variedades (regionais, culturais, estilísticas, temáticas, dialetais) as quais voltam o olhar para o social, para o outro, efetivando o uso interativo e reflexivo da língua. A utilização da literatura "requer sua leitura, sua discussão e sua perpetuação por meio de ações que se apropriem dela como instrumento de crescimento humano através da extrapolação de sentidos que a obra literária por si incita" (SEGABINAZI; SILVA, 2016, p. 235).

Dessa maneira, é possível compreender que pensar a aula de Língua Portuguesa desde o início da licenciatura, refletir sobre o planejamento, buscar fundamentos teóricos que embasem a metodologia, avaliar continuamente a prática, enfim, constituir a identidade profissional de forma consistente durante a formação inicial é de extrema relevância para que se tenham profissionais de excelência. Em vista disso, é inquestionável a importância da experiência prática promovida pelo PIBID aos acadêmicos do curso de Letras em formação inicial, pois se abrem espaços para o crescimento pessoal e profissional, bem como para o amadurecimento e para reflexões acerca do trabalho do professor.

\section{Leitura e produção textual: processos indispensáveis na aula de Língua Portuguesa}

A leitura caracteriza-se por ser uma prática interativa e social, a qual permite a compreensão da nossa alteridade e ambiência. Segundo Krug (2015, p. 5), "a leitura ultrapassa os limites da decodificação, efetivando-se como ação, que prepara leitores capazes de participarem da sociedade na qual estão inseridos e, acima de tudo, exercendo o direito e dever de transformá-la." Nessa perspectiva, a leitura contribui de forma significativa na formação do aluno e amplia suas visões, expandindo sua capacidade de interpretar questões sobre o mundo.

Busca-se um lugar de destaque para os processos de leitura e de produção textual (oral ou escrita) nas aulas de Língua Portuguesa, à medida que são instrumentos que estimulam a capacidade argumentativa, promovem a imaginação no desenvolvimento de textos e

\section{LINHA DÁGUA}


oportunizam ao aprendiz a socialização de saberes. Fala-se aqui de espaços que promovam a produção de uma leitura crítica, que permita o encontro entre texto, autor, leitor e mundo, possibilitando uma integração que desponte para novas concepções, novas descobertas, novos conhecimentos (ANTUNES, 2003).

Para Villardi (1999), saber ler significa refletir, pensar, estar a favor ou contra, comentar, trocar opinião, construir uma concepção de mundo, ser capaz de compreender o que nos chega por meio da leitura, analisando e se posicionando criticamente diante das informações colhidas, o que se constitui como um dos atributos que permitem exercer, de forma mais abrangente e complexa, a própria cidadania. A autora ainda ressalta que:

As leituras se fazem pelos sentidos em que e com que se dão. Lê-se pela visão, pela audição, pelo equilíbrio, pela contemplação intuitiva, pela meditação racional, pela força criadora da fantasia, da inventiva e da imaginação. Nas metáforas, por substituição do significado, é feita a melhor leitura do termo original. No mundo, lê-se por conta própria ou pelas leituras dos outros; leem-se as entrelinhas por trás das letras dos textos, e, na falta de espaço que justifica o etc., lê-se a continuidade da mensagem interrompida no texto. Ler é tomar conhecimento das leis, regras e normas, das necessidades e revelações do mundo, interpretá-las e utilizá-las. Infringi-las ou acatá-las é submeter-se às suas sanções - penas ou recompensas (VILLARDI, 1999, p. 3).

Assim, para interpretar um texto, o leitor deve ativar uma série de destrezas e estratégias interpretativas, atribuindo sentidos, constituindo-se e formando opiniões enquanto sujeitoleitor-crítico. O leitor criativo não é apenas um decodificador de palavras, ao contrário, busca uma compreensão do texto, dialogando com ele, recriando sentidos implícitos, fazendo inferências, estabelecendo relações, mobilizando seus conhecimentos para dar coerência às possibilidades significativas do texto.

A partir disso, pode-se perceber que a leitura e a produção textual estão longe de serem processos passivos, ou seja, para que ocorra o processo de interação, exige-se uma participação ativa do leitor/escritor em relação ao texto que se lê/produz. No que diz respeito à leitura, vale destacar que "a compreensão é uma forma de diálogo; ela está para a enunciação assim como uma réplica está para a outra no diálogo. Compreender é opor à palavra do locutor uma contrapalavra" (BAKHTIN, 2006, p. 135). Em vista disso, a significação somente ocorre "no processo de compreensão ativa responsiva" (BAKHTIN, 2006, p. 135).

Por sua vez, a produção de textos também exige uma compreensão ampla e crítica de uma dada situação. Segundo Geraldi (2010, p. 98), na escola, é preciso criar condições para que haja escrita: "um sujeito somente escreve quando tem o que dizer, mas não basta ter o que dizer, ele precisa ter razões para dizer o que tem a dizer". Somado a isso, o sujeito precisa ter clareza sobre quem é seu interlocutor, com quem estabelece um contexto de interação e de construção de atitudes responsivas ativas.

Nesse mesmo sentido, Kleiman destaca o conhecimento prévio como fundamental no processo de leitura, pois o leitor utiliza o que ele já sabe. Segundo a autora, "a leitura é

\section{LINHA D'ÁGUA}


considerada um processo interativo" (KLEIMAN, 2000, p.13). É através da interação de diferentes níveis de conhecimento, como o conhecimento linguístico, o textual e o conhecimento de mundo, que o leitor terá condições de significar o texto. Para a autora:

a compreensão é um processo altamente subjetivo, pois cada leitor traz à tarefa sua carga experiencial que determinará uma leitura para cada leitor num mesmo momento e uma leitura diferente para o mesmo leitor, em momentos diversos (KLEIMAN, 2000 p. 151).

Sob uma definição mais geral de leitura, Leffa (1996, p. 10) a considera basicamente como sendo "um processo de representação", o qual não ocorre de forma direta, mas, ao contrário, de forma mediada, em que entram em jogo ativamente outros elementos:

A leitura não se dá por acesso direto à realidade, mas por intermediação de outros elementos da realidade. Nessa triangulação da leitura o elemento intermediário funciona como um espelho; mostra um segmento do mundo que normalmente nada tem a ver com sua consistência física. Ler é, portanto, reconhecer o mundo através de espelhos. Como esses espelhos oferecem imagens fragmentadas do mundo, a verdadeira leitura só é possível quando se tem um conhecimento prévio desse mundo.

Em relação a uma definição mais restrita de leitura, Leffa (1996, p. 11) destaca a diferença entre "extrair significado do texto e atribuir significado ao texto". Conforme o autor, quando se fala em extração de significado, dá-se mais importância para o texto, pois se põe o significado em seu interior. Entretanto, quando se fala em atribuição de significado, dá-se maior destaque para o leitor, uma vez que se leva em consideração que cada leitor tem uma visão diferente da realidade, e fará sua leitura de acordo com a bagagem de experiências prévias que tiver.

Na mesma direção, Kato (1999, p. 68) destaca que "o leitor ideal é aquele que se apoia em seus conhecimentos prévios e que faz uso adequado desses processos. As estratégias serão determinadas por vários fatores: o grau de novidade do texto, o local do texto, o objeto de leitura, a motivação para a leitura etc.". A autora ainda destaca o fato de que "a leitura não pode ser vista como um processo que extrai o sentido final do texto, pois este é o elemento que delimita a gama de interpretações possíveis" (KATO, 1999, p. 71).

Sendo assim, os processos de leitura e de escrita, unidos ao debate e à troca de ideias, são fatores interdependentes e, quando colocados em prática no âmbito escolar, enriquecem o desenvolvimento das aulas, bem como auxiliam no processo evolutivo dos educandos. Essas atividades, no entanto, não são as únicas que integram os conhecimentos essenciais da área de Língua Portuguesa: a literatura também precisa estar presente no âmbito do ensino de língua materna, inclusive no Ensino Fundamental.

Sobre esse ponto, a Base Nacional Curricular Comum (BNCC) destaca que o objetivo maior do ensino de Língua Portuguesa é promover o acesso a saberes linguísticos que possibilitem ao estudante a participação social e o exercício da cidadania. Para isso, um dos eixos organizadores comuns que deve ser trabalhado no decorrer desse nível é o literário. $\mathrm{O}$

\section{LINHA DÁGUA}


eixo da Educação literária, conforme o documento, relaciona-se estreitamente com o eixo da leitura, contudo apresenta objetivos diferenciados. Enquanto no eixo da leitura busca-se possibilitar o desenvolvimento de habilidades de compreensão e de interpretação, por sua vez, no eixo da Educação literária:

predomina a formação para conhecer e apreciar textos literários orais e escritos, de autores de língua portuguesa e de traduções de autores de clássicos da literatura internacional. Não se trata, pois, no eixo Educação literária, de ensinar literatura, mas de promover o contato com a literatura para a formação do leitor literário, capaz de apreender e apreciar o que há de singular em um texto cuja intencionalidade não é imediatamente prática, mas artística. $\mathrm{O}$ leitor descobre, assim, a literatura como possibilidade de fruição estética, alternativa de leitura prazerosa. Além disso, se a leitura literária possibilita a vivência de mundos ficcionais, possibilita também ampliação da visão de mundo, pela experiência vicária com outras épocas, outros espaços, outras culturas, outros modos de vida, outros seres humanos (BRASIL, 2017, p. 65).

Nesse caminho, as práticas desenvolvidas durante o PIBID, aqui apresentadas, privilegiaram a leitura de textos da literatura - Dom Casmurro, de Machado de Assis, e "As mãos dos Pretos", de Luís Bernardo Honwana - a fim de propiciar o letramento literário. Com isso, houve articulação entre o eixo da leitura, uma vez que se buscou desenvolver capacidades de linguagem, sobretudo as de compreender e de interpretar, e com o eixo literário, visto que se promoveu o conhecimento e a apreciação de textos da literatura brasileira e literatura moçambicana, propiciando a formação literária do leitor. Ademais, por meio do gênero textual júri simulado na primeira prática, buscou-se não só desenvolver a produção de textos orais em um contexto determinado, mas também refletir criticamente sobre o texto literário, possibilitando a ampliação da visão de mundo dos estudantes. Para isso, ressaltou-se o papel da literatura na formação do leitor e nas práticas de letramento que podem ocorrer na escola.

Segabinazi e Silva (2016), ao vislumbrarem uma educação literária que esteja de acordo com o verdadeiro papel da literatura, abordam a questão da invisibilidade dessa área no processo de ensino e de aprendizagem nos anos finais do Ensino Fundamental. Essa constatação de apagamento é observada constantemente nos relatórios de estágio que supervisionam. Conforme as autoras, é interessante pensar nos motivos que levam à não utilização da literatura nas aulas de Língua Portuguesa: "entender como a leitura e a escrita literária sucumbem nas aulas de gramática e estudo das estruturas dos gêneros", ocasionando o apagamento da literatura no contexto escolar (SEGABINAZI; SILVA, 2016, p.232). Opondo-se a essa situação, ressaltam que é possível que o texto literário seja utilizado no processo de letramento; para isso, é necessário elucidar a relevante função da literatura na formação do leitor.

Cândido (2011) observa que, ao leitor de uma obra literária, é possível expor-se diante de distintas situações e experiências, o que resulta em seu envolvimento em uma rede de fatos e de informações. Em vista disso, o autor evidencia o caráter orientador e formativo do texto literário, visto que sua leitura pode propiciar reflexão e, consequentemente, mudança de comportamentos.

\section{LINHA DÁGUA}


Nessa lógica, cumpre destacar que se percebe o letramento literário como uma prática viável para a sala de aula. Assim, Cosson (2011) elabora uma sequência básica, que é dividida em quatro etapas. A primeira, chamada de motivação, é a preparação do contato do aluno com o texto. Para o autor, "Crianças, adolescentes e adultos embarcam com mais entusiasmo nas propostas de motivação e, consequentemente, na leitura quando há uma moldura, uma situação que lhes permite interagir de modo criativo com as palavras" (COSSON, 2011, p. 53-54). A segunda intitula-se introdução e é o momento de apresentação do autor e da obra e, por esse motivo, não deve ser muito extensa. A leitura é a terceira etapa, que compreende o acompanhamento da leitura, o momento de tirar dúvidas, de esclarecer certos pontos do texto, desde questões estruturais e formais até vocabulares e temáticas. A última parte é a interpretação, possuindo dois momentos: o interior e o exterior. No que diz respeito ao interior, trata-se do encontro do leitor com a obra; já o exterior é o espaço de discussão do texto lido, do compartilhamento de interpretações e do registro, que pode ser feito de diferentes maneiras: produção textual, música, escultura, maquete, dramatização, entre outras atividades.

Vale ressaltar que, no âmbito escolar, a criança deve ser instigada a conhecer diversos textos literários, sendo assim, essa leitura é imprescindível para que o educando desenvolva sua capacidade crítica e argumentativa, através de observações e posicionamentos adquiridos nesse processo. Nesse âmbito, buscou-se promover espaços para a interpretação e compreensão textual, como também reflexões e debates a partir da vivência de contextos ficcionais. Assim, a próxima seção visa mostrar a importância do uso do texto literário como objeto de ensino das práticas pedagógicas das aulas de Língua Portuguesa.

\section{A literatura nas aulas de Língua Portuguesa: letramento e formação}

Todas as questões apresentadas apontam para uma situação de ensino: o texto literário precisa fazer parte das aulas de Língua Portuguesa. Nesse sentido, ao se trabalhar com a formação inicial de docentes, no Curso de Letras e, sobretudo, no projeto do PIBID, buscou-se evidenciar a relevância dessa articulação. Soares (2012. p. 44) define letramento como "um estado, uma condição: o estado ou condição de quem interage com diferentes portadores de leitura e de escrita, com diferentes gêneros e tipos de leitura e de escrita, com as diferentes funções que a leitura e a escrita desempenham na nossa vida”. Em vista disso, ressaltou-se o papel da literatura na formação do leitor e nas práticas de letramento que podem ocorrer na escola:

Seguimos a perspectiva que protagoniza o leitor como constituidor de significação daquilo que lê em seu processo de formação literária. Valemo-nos de teorias que aprofundam e validam o processo de letramento literário a partir da obra literária em sua integralidade e levamos em consideração os apontamentos que discorrem sobre o risco do desaparecimento que a literatura tem sofrido no ambiente escolar, visto que é um dos agravantes da crise da leitura há muito constatada no contexto brasileiro (SEGABINAZI; SILVA, 2016, p. 233-234).

\section{LINHA D'ÁGUA}


Desse modo, apresentam-se, a seguir, duas práticas desenvolvidas durante o PIBID, as quais priorizaram a utilização do texto literário como ponto de partida para se trabalhar capacidades discursivas: ler, interpretar, refletir, analisar e produzir textos (orais).

A primeira prática apresentada foi realizada com uma turma de $9^{\circ}$ ano do Ensino Fundamental, com um total de 23 alunos. As aulas ocorriam uma vez por semana, nas quintasfeiras. A segunda prática apresentada foi realizada com uma turma de $8^{\circ}$ ano do Ensino Fundamental, com um total de 20 alunos. As aulas ocorriam uma vez por semana, nas terçasfeiras. O objetivo principal dos dois planos foi promover a formação do leitor literário, o desenvolvimento do senso crítico, da fundamentação de opiniões e da cidadania, por meio da leitura de textos literários.

Para dar conta disso, em relação à primeira prática, os alunos leram a obra Dom Casmurro, de Machado de Assis. Em seguida, após a problematização da história, os alunos fizeram a simulação de um tribunal do júri a fim de julgar a personagem Capitu (afinal, ela traiu ou não Bentinho?). No que diz respeito à segunda prática, foi lido o conto "As mãos dos pretos", de Luís Bernardo Honwana. Após a leitura do texto, debateu-se com os alunos sobre a problemática do preconceito racial em nossa sociedade. No próximo tópico, apresentam-se os procedimentos metodológicos por aula dada.

\section{Procedimentos metodológicos}

Partindo das informações expostas acima, para iniciar o trabalho, como atividade de motivação, abordou-se a obra Dom Casmurro (contextualização histórica, social, situação de produção, alcance etc.) e a biografia do autor Machado de Assis (apresentou-se, para aqueles que não conheciam, a trajetória do escritor). Além disso, falou-se, superficialmente, sobre a suposta traição da personagem Capitu, questão bastante polêmica da obra. Após isso, solicitouse a leitura do livro e foram dadas maiores explicações acerca da atividade que seria desenvolvida: a simulação do tribunal de um júri realizada pelos alunos, cuja ré seria a personagem da obra, Capitu. É importante destacar que a leitura da obra foi realizada no período de férias escolares, mais especificamente, no mês de julho de 2019. Assim, ao retornarem as aulas, a atividade foi retomada.

Posteriormente, trabalhou-se com a caracterização do gênero júri simulado: mostrou-se, a partir de vídeos, o que é, como funciona, para que serve, quais os integrantes, dentre outros aspectos, de um tribunal do júri. Para exemplificar, foram apresentados à turma alguns casos que tiveram grande repercussão (Julgamento de Fernandinho Beira Mar, Juri popular caso Bernardo). Também, expuseram-se os tipos de argumentos existentes, exemplificando-os por meio de alguns textos (petições, sentenças etc.).

Após finalizada a leitura da obra, na aula 2, em um primeiro momento, foi realizada a exploração do texto literário: atividades de discussão, de reflexão, de interpretação e de

\section{LINHA DÁGUA}


compreensão. Depois de uma longa problematização, com a finalidade de envolver os alunos ainda mais com o texto literário, organizou-se o júri simulado. Nesse sentido, Coracini (1999) destaca que não há sentido sem interpretação e não há interpretação sem que o sujeito tome o texto entre as mãos, sem que lhe acrescente um novo fio, isto é, sem que se envolva e nele deixe suas marcas. A partir da opinião de cada um, então, foram divididas as personagens em a)1 juiz, b) 3 advogados de defesa, c) 3 advogados de acusação, d) 1 ré (Capitu), e) 1 vítima (Bentinho), e) 1 testemunha da ré (Sancha), f) 1 testemunha da vítima (José Dias) e g) 12 integrantes do júri. As funções de cada personagem são dispostas conforme quadro abaixo.

Quadro 1. Funções das personagens do Tribunal do Júri da Capitu

a) Juiz (1) = Responsável por iniciar (breve relato do ocorrido), conduzir o julgamento e dar a sentença a partir do resultado do júri (no caso de condenação, criar uma pena);

b) Adv. Defesa (3) = Responsável pela defesa da ré (argumentos a favor da ré e contra a vítima). Os 3 advogados escreverão juntos somente um texto;

c) Adv. Acusação (3) = Responsável pela acusação da ré (argumentos contra a ré e a favor da vítima). Os 3 advogados escreverão juntos somente um texto;

d) Ré (1) = Responsável por representar a Capitu e expor sua versão;

e) Vítima (1) = Responsável por representar o Bentinho e expor sua versão;

f) Testemunha da ré (1) = Responsável por representar Sancha e contar algum fato que ajude na defesa da ré;

g) Testemunha da vítima (1) = Responsável por representar José Dias e contar algum fato que ajude na acusação da vítima;

h) Júri (12) = Responsáveis por julgar a ré (condenar ou absolver). Cada integrante vai expor seu julgamento e a maioria dos votos será a sentença dada pelo juiz.

Fonte: Plano de ensino.

$\mathrm{Na}$ aula 3, trabalhou-se com a atividade de produção textual: focalizaram-se as falas que constituiriam cada polo participativo: acusação, defesa, vítima, ré, testemunhas. Além do mais, os estudantes tiveram a oportunidade de ler, estudar e se preparar para a simulação do tribunal do júri. Para isso, buscaram se fundamentar nos fatos do livro e nos conhecimentos sobre gêneros opinativos e tipo de discurso argumentativo (tipos de argumentos, construção de argumentos etc.). Orlandi (1996a, p. 22) ressalta que "ao significar o sujeito se significa, o gesto de interpretação é o que - perceptível ou não para o sujeito e/ou para seus interlocutores decide a direção dos sentidos, decidindo, assim, sobre sua (sujeito) direção". Assim, tudo deveria ser finalizado, uma vez que, na próxima aula, ocorreria o júri, como apresentado abaixo.

$\mathrm{Na}$ aula 4, em um momento inicial, ocorreu a apresentação da simulação do tribunal do júri pelos alunos. Foi uma atividade bastante rica, a qual envolveu a todos. É pertinente destacar que a simulação foi gravada a fim de que os alunos pudessem assistir a suas performances posteriormente.

\section{LINHA D'́GUA}


Cabe destacar que, como mediador, o professor exerce um papel fundamental, que é o de promover o encontro entre texto e leitor (aluno) para que haja a produção de leitura. Porém, é preciso que o professor tenha cuidado para não cristalizar o conhecimento de seus alunos, querendo que eles tenham uma leitura única. É preciso levar os alunos a interagir com o texto e produzir, cada um, a sua própria leitura. Quanto a isso, Orlandi (1996b, p. 212) ressalta que "deve-se originar um espaço dado ao aluno para que ele mesmo elabore sua relação com a leitura, ou seja, é preciso não tirar seu poder de decisão, não pretender estar no seu lugar".

Dessa forma, em um segundo momento, retornou-se para a reflexão sobre a obra, para aspectos importantes que podem interferir na produção do sentido. Assim, expôs-se o fato de que a história do livro é narrada pelo próprio Bentinho, ou seja, baseada na sua versão dos acontecimentos. Diante disso, informou-se que existem outros livros que narram a mesma história, porém, baseada na versão da Capitu (como, por exemplo, A Audácia Dessa Mulher, de Ana Maria Machado, lançado em 1999, e Capitu-memórias póstumas, de Domício Proença Filho, lançado em 2005), no intuito de instigar a curiosidade dos alunos e continuar incentivando a leitura de obras literárias.

Para o segundo relato, o texto usado foi o conto “As mãos dos pretos", de Luís Bernardo Honwana. Por ser um texto mais breve, foram utilizadas quatro aulas sequenciais para a aplicação do plano, seguindo os passos da sequência básica, proposta por Cosson (2011). Para a aplicação do plano, foi escolhido o mês de novembro por ter entre suas datas comemorativas o dia da Consciência Negra.

A motivação foi feita como provocação para ajudar a desconstruir estereótipos e trazer mais informações sobre o continente africano. A primeira pergunta feita foi "qual é a língua falada na África?". O intuito da pergunta era mostrar que a África é um continente, não um país. Depois de ouvir algumas respostas, foi apresentado um quadro com todos os países do continente, a capital, o idioma oficial e a data de independência. A segunda pergunta foi para pensar a relação da Europa com a África “por que se falam idiomas europeus no continente?". A partir das respostas dos alunos, falou-se sobre a colonização europeia em países africanos, que impuseram sua língua e seus costumes a vários povos. Para finalizar a introdução, chamouse atenção para as cinco nações que falam português e a sigla usada para referir-se a elas: PALOP (Países Africanos de Língua Oficial Portuguesa).

$\mathrm{Na}$ introdução, apresentou-se o autor Luís Bernardo Honwana, nascido em Lourenço Marques (atual Maputo, capital de Moçambique) em 1942. Nós matamos o cão tinhoso é o único livro do escritor, publicado em 1964. A obra já foi traduzida para várias línguas, destacando as edições em inglês e russo, ainda nos anos 60. O autor é visto como uma influência desde então nas literaturas africanas de língua portuguesa, devido, principalmente, à denúncia que há ao colonialismo europeu e às mazelas sociais advindas dele.

A leitura teve três momentos. No primeiro, foi realizada a leitura individual pelos alunos. No segundo, a coletiva feita pelos alunos que se voluntariaram. A terceira deu-se pelas

\section{LINHA DÁGUA}


bolsistas do programa, destacando passagens, tirando dúvidas de vocabulário, assim como mostrando algumas diferenças entre a língua portuguesa falada no Brasil e em Moçambique.

Cosson (2011) aconselha duas etapas para a interpretação. Na primeira foram feitas questões sobre o texto, tais como: 1. A mãe e o filho são negros? 2. Por que ela se pôs a chorar depois de dar a explicação sobre a mão dos pretos ao filho?; 3. As respostas dadas ao garoto pelo Senhor Professor, pela Dona Dores e pelo Senhor Antunes da Coca-Cola podem ser consideradas preconceituosas?; 4. "Deve ter sido a pensar assim que Ele fez com que as mãos dos pretos fossem iguais às mãos dos homens que dão graças a Deus por não serem pretos. " Explique essa passagem e a relacione com o racismo; 5. Qual seria a sua resposta se alguém lhe perguntasse: "Por que as mãos dos pretos são mais claras que o resto do corpo?".

A segunda etapa foi a produção textual. Nela os alunos tiveram de produzir um conto a partir do seguinte excerto do texto: "O que os homens fazem, é feito por mãos iguais, mãos de pessoas que, se tiverem juízo, sabem que antes de serem qualquer outra coisa são homens". Como esse mote, a proposta era a escrita de uma nova história em que a promoção da igualdade racial aparecesse. Apesar de muitas das produções não fugirem muito da sugestão do conto de Honwana, elas demonstraram que os alunos compreenderam não só a proposta como também a importância da temática para a construção de uma sociedade mais justa e igualitária.

\section{Considerações finais}

A partir dos planos desenvolvidos e apresentados, é importante considerar que é possível o professor propor práticas de leitura que não limitem o texto apenas a questões puramente linguísticas, ligadas à estrutura sintática da língua, mas que também favoreçam a produção de sentidos e contribuam para o processo de constituição e humanização dos alunos como sujeitos. Ou, ainda, conforme propõe Orlandi (1996a, p. 37), "buscarmos, nos professores e alunos, um discurso pedagógico que seja pelo menos polêmico e que não nos obrigue a nos despirmos de tudo que é a vida lá fora ao atravessarmos a soleira da porta da escola”.

Dessa forma, destaca-se a importância do PIBID no processo de formação dos licenciandos em Letras, a partir das experiências vivenciadas durante a graduação, por meio da integração entre Educação Superior e Educação Básica das escolas estaduais e municipais. Nesse caminho, possibilitam-se espaços para oportunizar a produção e a participação dos licenciandos na busca de novas metodologias e práticas que favoreçam o processo de ensino e de aprendizagem.

Portanto, espera-se que este trabalho permita uma reflexão que leve os educadores a pensarem em metodologias, que possam trazer novas perspectivas ao ensino e, particularmente, ao modo de produção de leitura na escola, buscando, cada vez mais, práticas que favoreçam a constituição dos alunos em sujeitos-leitores-críticos.

\section{LINHA D'́GUA}


As reflexões apresentadas anteriormente partiram de duas preocupações centrais: o ensino de Língua Portuguesa e suas respectivas literaturas, assim como a divulgação de práticas que se consideram exitosas. Como já se destacou na introdução, a experiência docente dos autores aqui envolvidos, como professores de estágio, ex-coordenador e coordenadoras do PIBID, assim como a coordenação tanto de projetos de pesquisa quanto de extensão, voltados ao ensino, ajudou bastante. Essa experiência profissional, sem dúvida, possibilitou um olhar mais aguçado para questões didáticas e metodológicas do e no ensino de Língua Portuguesa e literatura na Educação Básica.

\section{Referências}

ANTUNES, I. Aula de Português: Encontro \& interação. São Paulo: Parábola Editorial, 2003.

ANTUNES, I. Muito Além da Gramática: por um ensino de línguas sem pedras no caminho. Ed. Parábola, 2007.

ASSIS, Machado de. Dom Casmurro. vol. 1. Nova Aguilar: Rio de Janeiro, 1994.

BAKHTIN, M. Marxismo e filosofia da linguagem: problemas fundamentais do método sociológico na ciência da linguagem. 12. ed. Trad. Michel Lahud e Yara Frateschi Vieira. São Paulo: Hucitec, 2006.

BRASIL. Ministério da Educação. Base Nacional Comum Curricular. Brasília, 2017. Disponível em: http://basenacionalcomum.mec.gov.br/a-base. Acesso em 11 jun. 2020.

BRASIL. Secretaria de Educação Fundamental. Parâmetros curriculares nacionais: terceiro e quarto ciclos do ensino fundamental: língua portuguesa. Brasília: MEC/SEF, 1998.

BRASIL. Parâmetros Curriculares Nacionais: Ensino Médio. 2000. Disponível em: http://portal.mec.gov.br/expansao-da-rede-federal/195-secretarias-112877938/seb-educacaobasica-2007048997/12598-publicacoes-sp-265002211 . Acesso em: 28 set. 2020.

BRASIL. Parâmetros Curriculares Nacionais: Língua Portuguesa. Brasília: MEC/SEF,1997. Disponível em: http://portal.mec.gov.br/seb/arquivos/pdf/livro02.pdf. Acesso em: 01 out. 2020.

CANDIDO, A. Vários escritos. 5. ed. Rio de janeiro: Outro sobre Azul, 2011.

CORACINI, M. J. (org.). Interpretação: autoria e legitimação do livro didático: língua materna e língua estrangeira. Campinas, SP: Pontes, 1999.

COSSON, R. Letramento Literário. 2. ed. São Paulo: Contexto, 2011.

GEHRING, F. M. M.; CASTELA, G. S. Formação Inicial de Professores de Língua Portuguesa: Potencialidades do PIBID. Linguagem em (Re)vista, v. 11, n. 21, jan./jun. p. 103-122, 2016. Disponível em: http://www.filologia.org.br/linguagememrevista/21/05.pdf . Acesso em: 02 nov 2021.

GERALDI, J. W. A aula como acontecimento. São Carlos: Pedro \& João Editores, 2010.

HONWANA, L. B. As mãos dos pretos. In: HONWANA, L. B. Nós matamos o cão tinhoso. São Paulo: Ática, 1980. p. 99-102.

KATO, M. A. O aprendizado da leitura. 5. ed. São Paulo: Marins Fontes, 1999.

\section{LINHA D'́GUA}


KLEIMAN, A. Texto e leitor: Aspectos cognitivos da leitura. 7. ed. - Campinas, SP: Pontes, 2000.

KRUG, F. S. A Importância da leitura na formação do leitor. REI-Revista de Educação do IDEAU, v. 10, n. 22, p. 1-13, 2015. Disponível em: https://www.getulio.ideau.com.br/wpcontent/files mf/b80cee602abb950b63a6d6c5cb43df40277 1.pdf. Acesso em: 02 nov 2021

LEFFA, V. Aspectos de leitura. Porto Alegre, Sagra: DC Luzzatto, 1996.

ORLANDI, E. P. Interpretação. Rio de Janeiro: Vozes, 1996a.

ORLANDI, E. P. A linguagem e seu funcionamento: as formas do discurso. $4^{\mathrm{a}}$ ed. Campinas, SP: Pontes, 1996b.

MACHADO, A. M. A audácia dessa mulher. Rio de Janeiro: Nova Fronteira, 1999.

MARCUSCHI, L. A. Compreensão de texto: algumas reflexões. In: DIONISIO, Angela Paiva; BEZERRA, Maria Auxiliadora. O livro didático de Português: múltiplos olhares. Rio de Janeiro: Lucerna, 2001. p. 46-59.

PROENÇA FILHO, D. Capitu-memórias póstumas. Rio de Janeiro: Editora Record, 2005.

SANTOS, M. L. A expressão livre no aprendizado da Língua Portuguesa. São Paulo: Scipione, 1996.

SEGABINAZI, D. M.; SILVA, R. S. Ler e escrever literatura também é aula de língua portuguesa. CERRADOS, v. 25, p. 229-244, 2016. Disponível em: https://periodicos.unb.br/index.php/cerrados/issue/view/1776/445 Acesso em: 02 nov 2021

SOARES, M. Letramento: um tema em três gêneros. 3. ed. Belo Horizonte: Autêntica, 2012.

VILLARDI, R. Ensinando a gostar de ler e formando leitores para a vida inteira. Rio de Janeiro: Qualitymark/Dunya Ed., 1999.

Recebido: 29/04/2021.

Aprovado: 02/08/2021. 